DOI: $\underline{\text { https://doi.org/10.24867/15BE10Stojanac }}$

\title{
UPRAVLJANJE PRETVARAČIMA SA 2 I VIŠE NIVOA U ULOZI SINHRONVERTORA - INVERTORA KOJI OPONAŠAJU RAD SINHRONIH GENERATORA
}

\section{CONTROL OF 2 LEVEL AND MULTILEVEL CONVERTERS IMPLEMENTED INTO SYNCHONVERTERS - INVERTERS THAT MIMIC SYNCHRONOUS GENERATORS}

\author{
Nemanja Stojanac, Marko Vekić, Fakultet tehničkih nauka, Novi Sad
}

\section{Oblast - ELEKTROTEHNIKA I RAČUNARSTVO}

Kratak sadržaj - Ovaj rad bavi se upravljanjem pretvaračima energetske elektronike (sa naglaskom na kaskadnim $H$ - mostovima) u ulozi sinhronvertora.

Ključne reči: Kaskadni $H$ - mostovi, sinhronvertor, Matlab Simulink

Abstract - This paper is about control of power electronic converters (with the focus on Cascaded $H-$ bridges) implemented into syncrhonverters.

Keywords: Cascaded H-bridges, synchronverters, Matlab Simulink

\section{UVOD}

Težnja za smanjenjem emisije ugljen-dioksida $u$ atmosferu dovodi do usmeravanja razvoja elektroenergetskih sistema ka obnovljivim izvorima energije kao što su sunčeva svetlost (fotonaponski paneli) i vetar (vetrogeneratori). U tradicionalnom elektroenergetskom sistemu preovlađuju sinhroni generatori čije obrtne karakteristike igraju značajnu ulogu u balansiranju zahteva potrošača. Zbog tromosti rotora, prelazni procesi će biti blagi i bez ugrožavanja stabilnosti sistema.

Mana obnovljivih izvora je što u sebi sadrže pretvarače energetske elektronike koji su neinertni elementi. Zbog povećanog broja obnovljivih izvora energije inertnost celog sistema opada, što dovodi u pitanje stabilnost sistema. Neinertnost dovodi do naglih promena učestanosti sistema pri manjim promenama u aktivnoj snazi.

Jedan od načina da se prevaziđe nedostatak inertnosti u sistemu je da se pretvarači energetske elektronike prilagode radu koji će oponašati rad sinhronih mašina. U radu je, kao jedna od mogućnosti, opisana primena sinhronvertora [1].

\section{KASKADNI H - MOSTOVI (CHB)}

Kaskadni $\mathrm{H}$ - mostovi spadaju u modularne pretvarače sa više nivoa. Modularne pretvarače odlikuje veći broj modula (ćelija) koji se međusobno povezuju [2]. Prednost modularnih pretvarača sa više nivoa u odnosu na ostale topologije je ostvarivanje značajnijih napona korišćenjem komponenata za manje napone, kao i jednostavna zamena neispravnih ćelija u slučaju kvara.

\section{NAPOMENA:}

Ovaj rad proistekao je iz master rada čiji mentor je bio dr Marko Vekić, vanr. prof.

\subsection{Topologija CHB}

Jedan kaskadni $\mathrm{H}$ - most prikazan je na slici 1 .

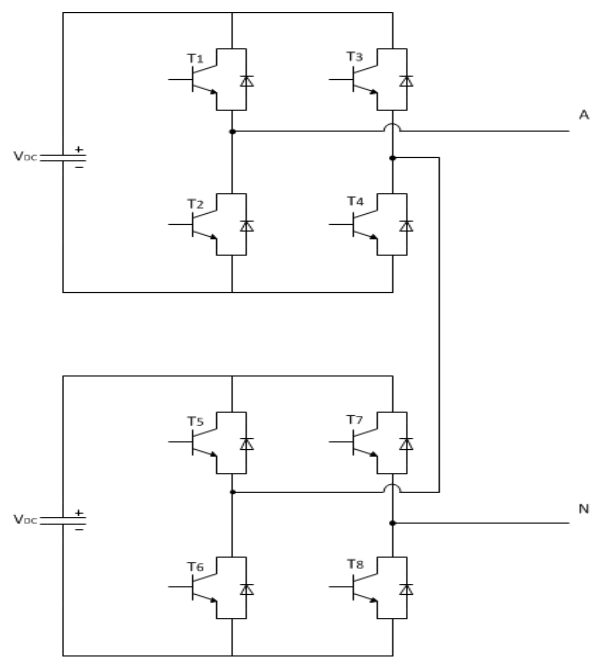

Slika 1. CHB sa 5 nivoa

Jedan $\mathrm{H}$ - most (jedna ćelija) može da ostvari 3 nivoa: $+\mathrm{V}_{\mathrm{DC}}, 0,-\mathrm{V}_{\mathrm{DC}}$. Ukoliko obe ćelije $\mathrm{CHB}-\mathrm{a}$ sa slike 1 doprinose pozitivnom naponu, ostvariće se naponski nivo $+2 \mathrm{~V}_{\mathrm{DC}}$. Sličnim kombinovanjem izlaznih napona dve ćelije ovakav $\mathrm{CHB}$ ostvaruje ukupno 5 različitih naponskih nivoa: $+2 \mathrm{~V}_{\mathrm{DC}},+\mathrm{V}_{\mathrm{DC}}, 0,-\mathrm{V}_{\mathrm{DC}},-2 \mathrm{~V}_{\mathrm{DC}}$.

\subsection{Fazno pomereni PWM (PS PWM)}

Od mnoštva tehnika modulacije pretvarača sa više nivoa biće opisana fazno pomerena impulsno širinska modulacija (PS PWM, Phase Shifted Pulse Width Modulation).

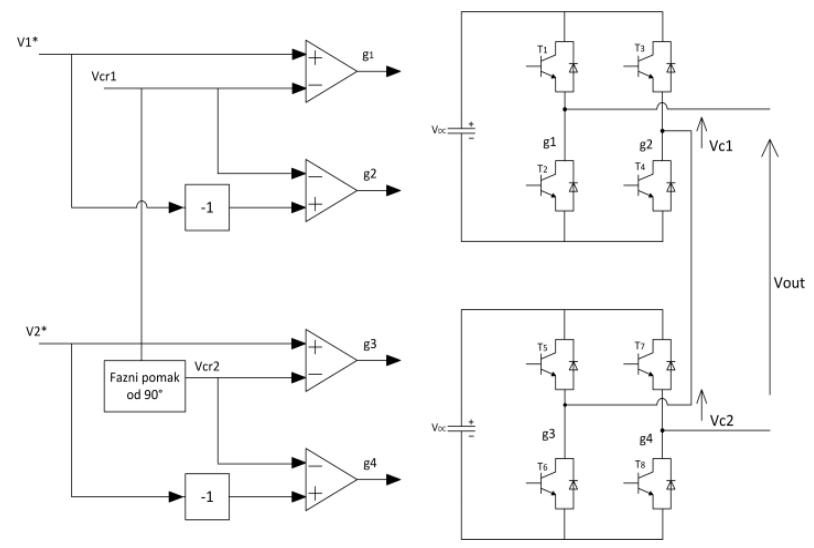

Slika 2. Implementacija PS PWM 
Svaka ćelija je modulisana nezavisno poređenjem modulišućeg i nosećeg signala. Modulišući signal je isti za sve ćelije iste faze, dok je noseći signal fazno pomeren za $180 \mathrm{deg} / \mathrm{n}$, gde je n broj ćelija jedne faze. Hardverska implementacija data je na slici 2. Izlazni napon $V_{\text {out }}$ jednak je zbiru napona na izlazu ćelija.

\section{SINHRONVERTOR}

Kombinovanjem energetske efikasnosti energetskih pretvarača u odnosu na sinhrone generatore, kao i osobine inertnosti sinhronih generatora, sinhronvertori postižu bilans aktivne snage (frekvencije) na efikasan način, bez ugrožavanja stabilnosti sistema. Pored toga, sinhronvertori mogu imati i ulogu STATCOM-a (statički sinhroni kompenzator) i učestvovati u kompenzaciji reaktivne snage (popravke sačinioca snage) ili obavljati nadzor napona zajedničke sabirnice. Načela rada sinhronvertora mogu se primeniti kako na pretvarače energetske elektronike sa dva nivoa, tako i na pretvarače s više nivoa.

\subsection{Matematički model sinhronog generatora}

Šema sinhronog generatora data je na slici 3.

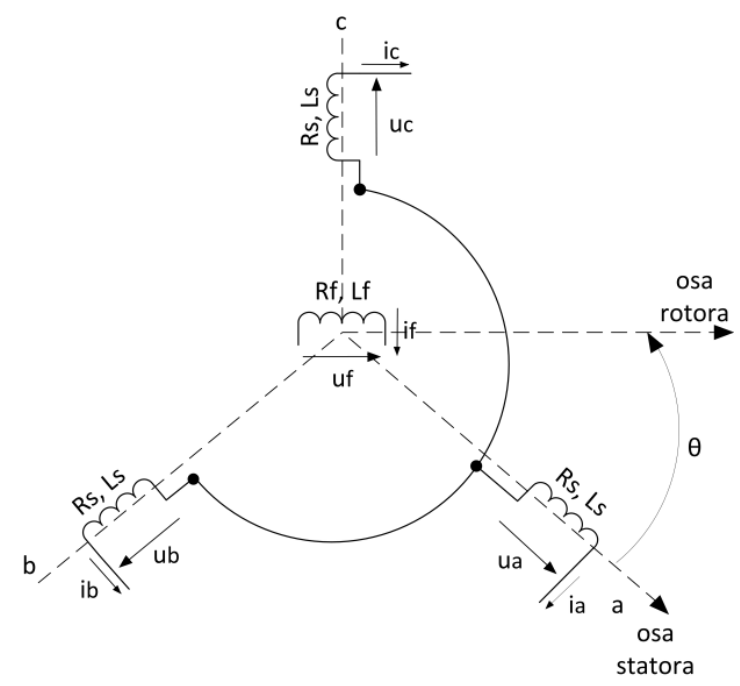

Slika 3. Šema sinhronog generatora [3]

Matematički model se sastoji iz izraza za naponsku ravnotežu statora i izraza za fluksne obuhvate statora i rotora, kao i Njutnove jednačine kretanja:

$$
\begin{gathered}
\underline{u}=-R_{s} \underline{i}-\frac{d \underline{\Phi}}{d t}=-R_{s} \underline{i}-L_{s} \frac{d \underline{i}}{d t}+\underline{e} \\
\underline{\Phi}=L_{s} \underline{i}+M_{f} i_{f} \widetilde{\cos } \theta \\
\left.\Phi_{f}=L_{f} i_{f}+M_{f} \underline{i}^{T} \times \widetilde{\cos } \theta\right) \\
\Phi_{a}=L_{s} i_{a}-M i_{b}-M i_{c}+M_{a f} i_{f} \\
\Phi_{b}=-M i_{a}+L_{s} i_{b}-M i_{c}+M_{b f} i_{f} \\
\Phi_{c}=-M i_{a}-M i_{b}+L_{s} i_{c}+M_{c f} i_{f} \\
\Phi_{f}=M_{a f} i_{a}+M_{b f} i_{b}+M_{c f} i_{c}+L_{f} i_{f}
\end{gathered}
$$

gde su:

$$
\begin{array}{ll}
- & \underline{\Phi}=\left[\begin{array}{lll}
\Phi_{a} & \Phi_{b} & \Phi_{c}
\end{array}\right]^{T} \\
- & \underline{i}=\left[\begin{array}{lll}
i_{a} & i_{b} & i_{c}
\end{array}\right]^{T}
\end{array}
$$

$-\quad \underline{u}=\left[\begin{array}{lll}u_{a} & u_{b} & u_{c}\end{array}\right]^{T}$

$-\underline{e}=\left[e_{a} e_{b} e_{c}\right]^{T}$

- $\widetilde{\cos } \theta=\left[\cos \theta \cos \left(\theta-\frac{2 \pi}{3}\right) \cos \left(\theta-\frac{4 \pi}{3}\right]^{T}\right.$

- $\quad M$ - međusobna induktivnost statorskih namotaja

- $L_{S}$ - samoinduktivnost statorskih namotaja

- $\quad M_{a f}, M_{b f}, M_{c f}$ - međusobne induktivnosti faznih namotaja statora i namotaja rotora

- $\quad L_{f}$ - samoinduktivnost rotorskog namotaja

- $i_{a}, i_{b}, i_{c}, i_{f}$ - fazne struje statora i rotora

Izraz za kontra-elektromotornu silu glasi:

$$
\underline{e}=M_{f} i_{f} \omega \widetilde{\sin } \theta-M_{f} \frac{d i_{f}}{d t} \widetilde{\cos } \theta
$$

gde je: $\widetilde{\sin } \theta=\left[\sin \theta \sin \left(\theta-\frac{2 \pi}{3}\right) \sin \left(\theta-\frac{4 \pi}{3}\right]^{T}\right.$

Njutnova jednačina kretanja glasi:

$$
J \frac{d \omega}{d t}=M_{m}-M_{e}-D_{p} \omega
$$

Veličina $J$ predstavlja moment inercije, $M m$ moment opterećenja, Me elektromagnetni moment, dok $D_{p}$ predstavlja faktor prigušenja (koeficijent trenja kod fizičkog generatora).

Izraz za elektromagnetni moment dobija se iz izraza za energiju sadržanu u magnetnom kolu:

$$
M_{e}=-\frac{\partial W}{\partial \theta_{m}}
$$

Tako je izraz za elektromagnetni moment jednak:

$$
M_{e}=p M_{f} I_{f}\left(\underline{i}^{T} \times \widetilde{\sin } \theta\right)
$$

Za upravljanje sinhronvertorom bitni su još i izrazi za aktivnu i reaktivnu snagu koji se dobijaju kao:

$$
\begin{gathered}
P=\underline{i}^{T} \times \underline{e} \\
Q=-\underline{i}^{T} \times \underline{e_{g}}
\end{gathered}
$$

gde $e_{g}=M_{f} i_{f} \omega \widetilde{\cos } \theta$ predstavlja signal amplitude kao elektromotorna sila, ali je zakašnjen za $90^{\circ}$.

Krajnji izrazi za aktivnu i reaktivnu snagu slede:

$$
\begin{gathered}
P=\omega M_{f} i_{f}\left(\underline{i}^{T} \times \widetilde{\sin } \theta\right) \\
Q=-\omega M_{f} i_{f}\left(\underline{i}^{T} \times \widetilde{\cos } \theta\right)
\end{gathered}
$$

\subsection{Primena invertora u ulozi sinhronvertora}

Sinhronvertor se sastoji iz dva dela: energetike (slika 4) i upravljačke elektronike (slika 5).

Energetika se sastoji iz trofaznog invertora, LC filtra (sa uvaženim otpornostima), sprežnog RL filtra i prekidača za priključenje na mrežu.

Uloga LC filtra je kako da oponaša otpornosti i induktivnosti namotaja sinhrone mašine, tako i da filtrira prekidački napon kako bi se dobio približno sinusan oblik kao što je slučaj kod sinhrone mašine. 


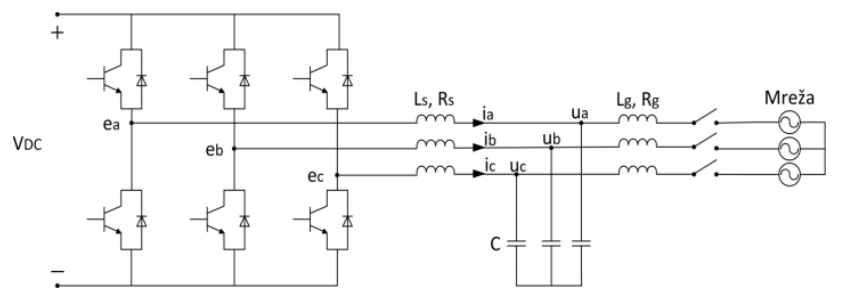

Slika 4. Energetski deo sinhronvertoraž

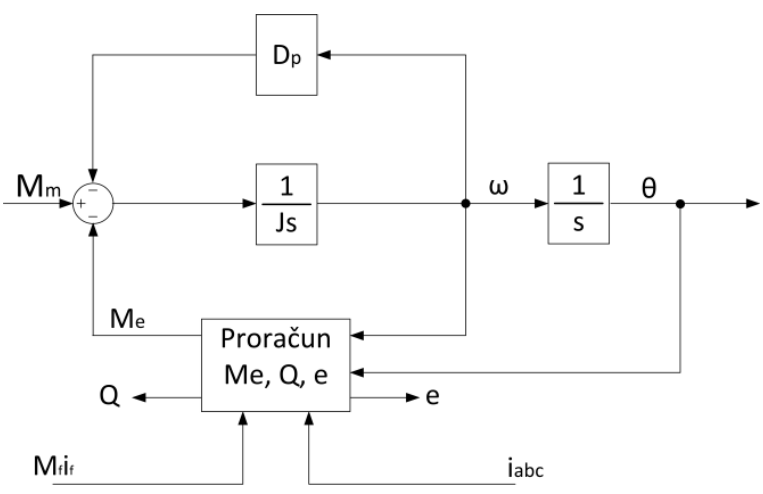

Slika 5. Upravljačka elektronika

Upravljačka elektronika se sastoji iz Njutnove jednačine kretanja i sklopova za proračun elektromagnetnog momenta, reaktivne snage i reference elektromotorne sile. Ulazi u upravljački slop su moment opterećenja i virtuelni fluks rotora $\mathrm{M}_{\mathrm{f}} \mathrm{I}_{\mathrm{f}}$, dok promenljive stanja su struje statora, virtuelna ugaona brzina i virtuelni ugao.

\subsection{Dejstvo sinhronvertora}

Kao što je već rečeno, sinhronvertorom se želi postići inertan rad pretvarača energetske elektronike. U nastavku su opisana dva bitna dela za upravljanje sinhronvertora, a to su frekventna $(\mathrm{Pf})$ i naponska $(\mathrm{QV})$ droop kontrola.

\subsubsection{Pf regulacija}

Pf regulacija se ostvaruje jednostavno proširenjem upravljačke elektronike sinhronvertora. Za droop kontrolu može se iskoristiti faktor prigušenja koji se proračunava kao odnos promene mehaničkog momenta usled promene virtuelne ugaone učestanosti:

$$
D_{p}=\frac{\Delta M_{m}}{\Delta \omega}=\frac{\Delta M_{m}}{M_{m n}} \frac{\omega_{n}}{\Delta \omega} \frac{M_{m n}}{\omega_{n}}
$$

Izmenjeni upravljački sklop prikazan je na gornjem delu slike 6. Mehanički moment zadaje se indirektno zadavanjem aktivne snage.

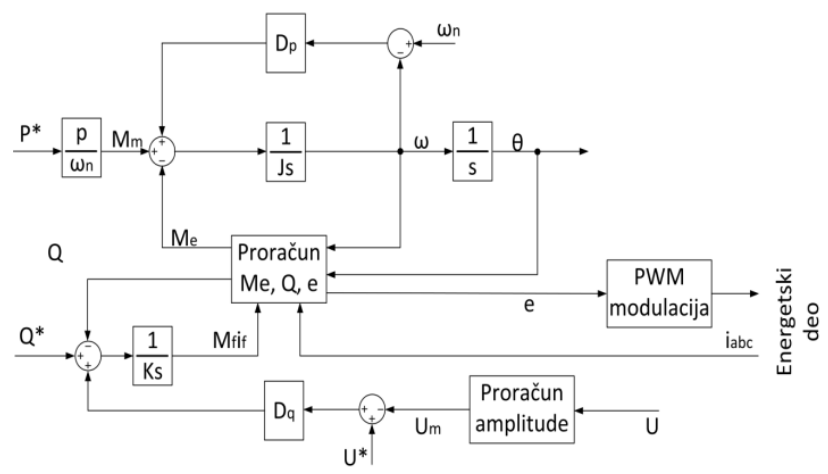

Slika 6. Blok algoritam rada sinhronvertora
Moment inercije bira se spram proračunatog faktora prigušenja i željene vremenske konstante frekventne petlje:

$$
J=D_{p} \tau_{f}
$$

\subsubsection{QV regulacija}

Algoritam QV regulacije prikazan je na donjem delu slike 7. Zadaju se reaktivna snaga i amplituda faznog napona.

Faktor $\mathrm{D}_{\mathrm{q}}$ predstavlja analogiju faktoru prigušenja $\mathrm{D}_{\mathrm{p}}$, dok koeficijent $\mathrm{K}$ predstavlja analogiju momentu inercije.

Faktor $\mathrm{D}_{\mathrm{q}}$ se proračunava spram odnosa promene reaktivne snage po promeni napona:

$$
D_{q}=\frac{\Delta Q}{\Delta V}=\frac{\Delta Q}{Q_{n}} \frac{V_{n}}{\Delta V} \frac{Q_{n}}{V_{n}}
$$

Koeficijent $K$ se proračunava spram faktora $D_{q} i$ vremenske konstante naponske petlje.

$$
K=\omega_{n} D_{q} \tau_{v}
$$

\section{STATCOM-ski rad sinhronvertora}

Sinhronvertor se može prilagoditi STATCOM-skom režimu rada. Potrebno je izmeniti upravljačku elektroniku dok energetski deo zadržava isti izgled (slika 7).

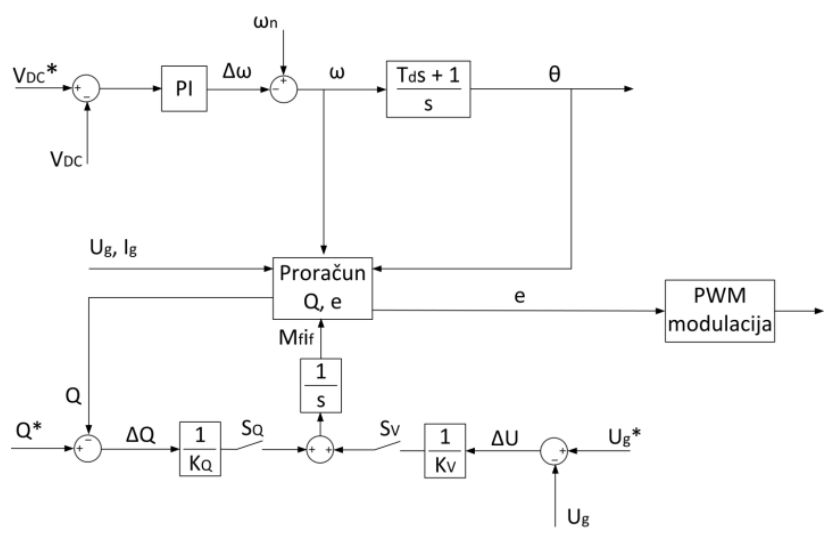

Slika 7. Upravljačka elektronika sinhrovertora $u$ STATCOM-skom režimu

STATCOM-ski rad podrazumeva kontrolu napunjenosti kondenzatora jednosmernog kola putem razmene aktivne snage (podešavanjem virtuelnog ugla $\theta$ ), kao i regulaciju reaktivne snage odnosno napona sabirnice zajedničkog priključenja putem zadavanja virtuelnog fluksa (elektromotorne sile).

\section{SIMULACIJE SINHRONVERTORA}

Simulacije su vršene u Matlab Simulink okruženju.

\subsection{Pf regulacija}

Faktor prigušenja proračunat je tako da se za $0,5 \%$ promene učestanosti aktivna snaga (moment) menja za $100 \%$.

Izgled faznih struja i virtuelnog fluksa dat je na slici 8 . 

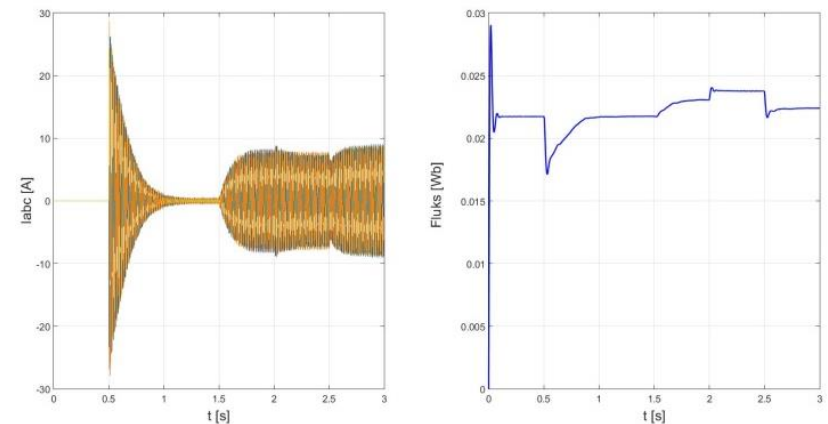

Slika 8. Fazne struje (levo) $i$ virtuelni fluks (desno)

Izgled faznih struja identičan je strujama statora sinhronog generatora.

Na slici 9 prikazani su učestanost i aktivna snaga.
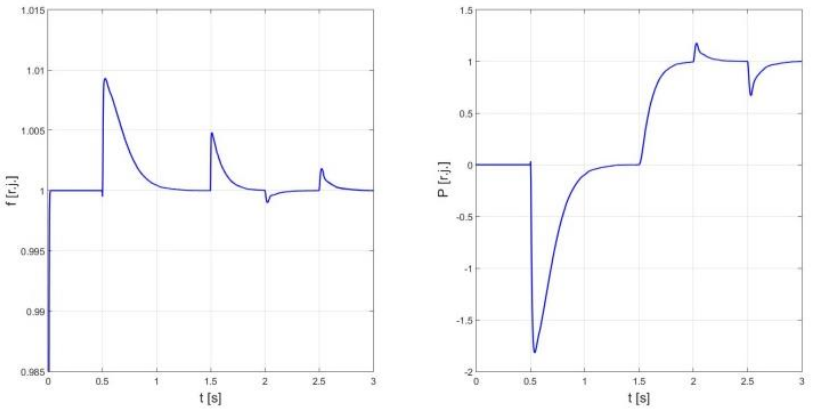

Slika 9. Učestanost (levo) i aktivna snaga (desno)

U 0,5 s sinhronvertor se priključuje na mrežu. Dolazi do propada snage i porasta frekvencije, koji se u kratkom roku vraćaju na zadate vrednosti. U trenutku $1,5 \mathrm{~s}$ zadaje se mehanička snaga od $1 \mathrm{r} . \mathrm{j}$, kad dolazi do porasta frekvencije za 0,5\%. Posle izvesnog vremena snaga dostiže zadatu vrednost dok se frekvencija vraća na nominalnu.

\subsection{STATCOM-ski režim}

Na slici 10 prikazani su odzivi virtuelne ugaone brzine $i$ napona na kondenzatoru jednosmernog kola. Uočava se da se DC napon kreće okvirima zadate vrednosti.
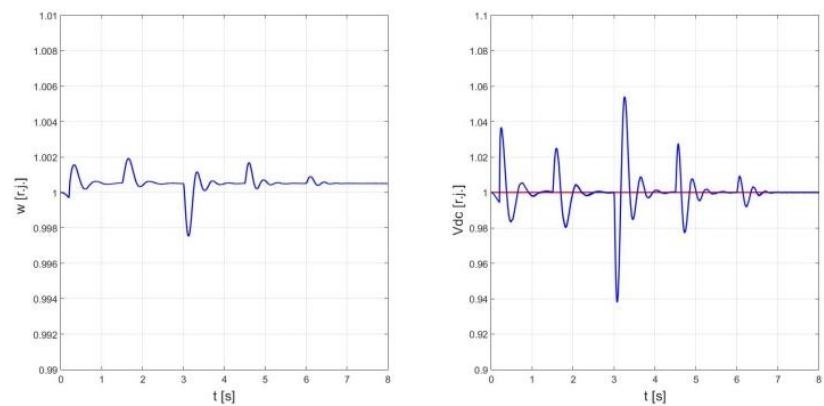

Slika 10. Ugaona brzina (levo) i DC napon (desno)

$\mathrm{Na}$ slici 11 prikazani su odzivi napona sabirnice zajedničkog priključenja i reaktivne snage. Sve do $3 \mathrm{~s}$ aktivan je prekidač $S_{\mathrm{V}}$ čime je STATCOM u režimu regulacije napona, prvo na nominalnu vrednost a zatim na vrednost $95 \%$. Nakon 3s STATCOM prelaži u režim regulacije reaktivne snage na zadatu vrednost od $100 \%$.
Nakon 4,5s nastupa droop režim u kom su aktivna oba prekidača istovremeno, te se napon i reaktivna snaga menjaju po droop karakteristici spram zadatih vrednosti.
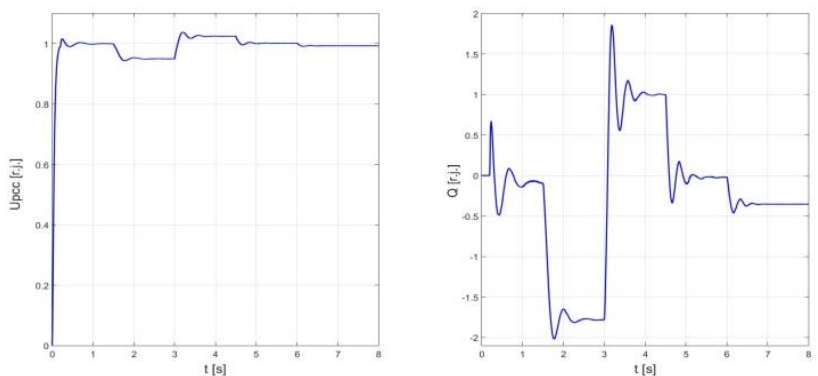

Slika 11. Napon PCC (levo) i reaktivna snaga (desno)

\section{ZAKLJUČAK}

Kako je potreba za veštačkom inercijom nastala nedavno sa rastom obnovljivih izvora sinhronvertori su još uvek fazi istraživanja. Ono što je sigurno je da će uređaji poput sinhronvertora biti predmet istraživanja u narednim godinama i da će naći svoju ulogu u rešavanju izazova nadolazećih mikromreža i pametnih mreža.

\section{LITERATURA}

[1] Q.-C Zhong and G. Weiss, "Synchronverters: Inverters that mimic synchronous generators" IEEE Trans. Ind. Electron., vol. 58, no. 4, pp. 1259-1267, Apr. 2011.

[2] M. Marchesoni, M. Mazzucchelli, and S. Tenconi, "A nonconventional power converter for plasma stabilization," IEEE Transactions on Power Electron, vol. 5, no. 2, pp. 212-219, Apr 1990.

[3] A. E. Fitzgerald, C. Kingsley, "Electric Machinery", vol 6, 1962.

[4] J. Rodriguez, L. Franquelo, S. Kouro, J. Leon, R. Portillo,M. Prats, and M. Perez, "Multilevel converters: An enabling technology for high-power applications," Proceedings of the IEEE, vol. 97, no. 11, pp. 1786-1817, Nov 2009.

\section{Kratka biografija:}

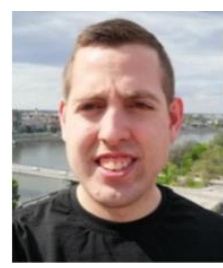

Nemanja Stojanac rođen je u Novom Sadu 1995. god. 2014. godine upisuje osnovne akademske studije na Fakultetu tehničkih nauka u Novom Sadu, smer energetika, elektronika i

telekomunikacije. Nakon završenih osnovnih studija 2020. godine upisuje master akademske studije na Fakultetu tehničkih nauka u Novom Sadu.

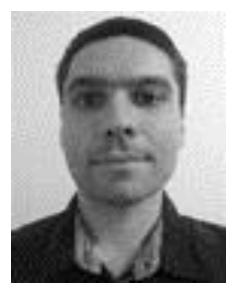

Marko Vekić je vanredni profesor na Fakultetu tehničkih nauka u Novom Sadu, na Katedri za Energetsku elektroniku i pretvarače. Oblasti interesovanja su mu energetska elektronika u prenosnim i distributivnim mrežama, mikromreže i kvalitet električne energije. 